\title{
Comparing the inflammatory profiles for incidence of diabetes mellitus and cardiovascular diseases: a prospective study exploring the 'common soil' hypothesis
}

Xue Bao ${ }^{1,2^{*}}$, Yan Borné2 ${ }^{2}$ Linda Johnson ${ }^{2}$, Iram Faqir Muhammad ${ }^{2}$, Margaretha Persson ${ }^{2}$, Kaijun Niu ${ }^{1}$ and Gunnar Engström²

\begin{abstract}
Background: Chronic low-grade inflammation and associated insulin resistance and metabolic abnormalities have been proposed as 'common soil' for diabetes mellitus (DM) and cardiovascular disease (CVD). This paper aimed to investigate the inflammatory profiles of DM and CVD and to distinguish their shared and specific markers.

Methods: Based on the Malmö Diet and Cancer cohort, total and differential leukocyte counts were measured in 25,969 participants without previous DM or CVD and were studied in relation to incident DM (mean follow-up $17.4 \pm 5.58$ years) and incident CVD (i.e., coronary events, including fatal and nonfatal myocardial infarction, or stroke); mean follow-up $17.7 \pm 5.46$ years, using multivariable Cox regression models. Furthermore, plasma concentrations of another seven inflammatory markers were examined in relation to incident DM and incident CVD in a sub-cohort of 4658 participants. The associations of each inflammatory marker with incident DM versus incident CVD were compared using the Lunn-McNeil competing risks approach. In sensitivity analyses, those who developed both DM and CVD during follow-up were excluded.

Results: After adjustment for conventional risk factors, total and differential leukocyte counts, orosomucoid, and C-reactive protein were associated with an increased risk of both DM and CVD. Neutrophil to lymphocyte ratio, ceruloplasmin, alpha1-antitrypsin and soluble urokinase plasminogen activator receptor predicted increased risk of CVD but not DM, while haptoglobin and complement C3 showed the opposite pattern. In competing risks analyses, lymphocyte count and complement C3 had stronger associations with risk of DM than with risk of CVD ( $p$ for equal associations $=0.020$ and 0.006 ). The reverse was true for neutrophil to lymphocyte ratio ( $p$ for equal associations $=0.025$ ). Results were consistent in sensitivity analyses.

Conclusions: The results indicated substantial similarities in the inflammatory profiles associated with DM and CVD. However, there are also significant differences. These findings may help discriminate between individuals at elevated risk of DM and those at elevated risk of CVD, which is a prerequisite for targeted therapies.
\end{abstract}

Keywords: Diabetes mellitus, Cardiovascular diseases, Cohort study, Inflammatory markers, Proportional hazards models, Survival analysis, Competing risks analysis

\footnotetext{
*Correspondence: xue.bao@med.lu.se

${ }^{2}$ Department of Clinical Sciences, Lund University, CRC 60:13, Jan

Waldenströms gata 35, 20502 Malmö, Sweden

Full list of author information is available at the end of the article
} 


\section{Background}

Diabetes mellitus (DM) is a well-known risk factor for cardiovascular disease (CVD) [1]. It has also been shown that CVD risk factors predict incident DM $[2,3]$. The overlapping risk factors for DM and CVD support a hypothesis that the two diseases share common antecedents [4]. This view is further supported by shared molecular drivers, pathways, and gene subnetworks for DM and CVD that have recently been discovered using genetic and functional data from multiple human cohorts [5]. A vast overlap in gene expression alterations has also been identified in obesity-driven insulin resistance (IR) and atherosclerosis, which are critical pathogenic mechanisms underlying DM and CVD, respectively [6]. Moreover, many of these alterations are related to the inflammatory response pathway [6]. Chronic low-grade inflammation and associated IR and metabolic abnormalities thus constitute a possible 'common soil' for DM and CVD [7-9].

Though inflammation is firmly established as central to the development of both DM and CVD, its importance in the pathogenesis may differ between DM and CVD [9-11]. The specific inflammatory processes involved in DM versus CVD may differ as well [12-15]. In DM, enlarged adipocytes and altered secretion of adipokines play a significant role in promoting inflammation in adipose tissue [16]. Islet $\beta$-cell dysfunction and IR, induced by inflammation, are involved in the pathogenesis of DM $[6,7]$. Other inflammation-related mechanisms, such as endothelial dysfunction, atherosclerosis and increased plaque vulnerability, play important roles in CVD $[6,8]$. For these reasons, it is possible that the inflammatory profiles are different for DM and CVD.

A wide range of inflammatory markers have been proposed as risk factors for both DM and CVD [3, 7, 8, 17-23]. Among them, several markers have already been widely studied, such as total and differential leukocyte counts [17-23] and C-reactive protein (CRP) $[3,7,8]$. However, correlations among markers have usually been weak or moderate [24, 25], which indicates that they potentially reflect different aspects of inflammation. For clinical purposes, it is necessary to identify reliable and specific markers that can help to discriminate between elevated risks of DM and CVD to enable targeted therapies.

Therefore, we conducted the present study to investigate the inflammatory profiles of DM and CVD and to distinguish their shared and specific markers.

\section{Materials and methods Participants}

The Malmö Diet and Cancer study (MDCS) is a large prospective cohort study. Subjects were recruited from the general population from Malmö, a southern city of Sweden (participation rate: 40.8\%) [26]. A baseline examination was conducted on 11,246 males and 17,203 females between March 1991 and September 1996 and included peripheral venous blood samples, physical examination, and a self-administered questionnaire. Of the initial 28,449 participants, complete information on leukocyte counts and covariates was available for 27,952 participants (Additional file 1). Twenty-two subjects with total leukocyte count higher than $20 \times 10^{9} / \mathrm{L}$ were excluded to rule out severe inflammation [27]. We further excluded 1214 subjects with previous DM and 747 subjects with previous CVD. The final study population consisted of 25,969 participants (9843 males and 16,126 females, aged $45-73$ years). Based on this cohort, total and differential leukocyte counts, as well as neutrophil to lymphocyte ratio (NLR), were studied in relation to DM and CVD (cohort analysis 1).

In addition, another seven inflammatory markers, including ceruloplasmin, alpha1-antitrypsin, orosomucoid, haptoglobin, complement C3, CRP and soluble urokinase plasminogen activator receptor (suPAR), were investigated in relation to DM and CVD using a sub-cohort of MDCS, the Malmö Diet and Cancer Cardiovascular cohort study (MDC-CV) [28]. In the MDC$\mathrm{CV}, 6103$ participants were randomly selected from the MDCS between 1991 and 1994 to study the epidemiology of carotid artery disease. From the MDC-CV 875 subjects were excluded due to missing data on waist circumference, smoking, low-density lipoprotein (LDL), or fasting glucose. Four hundred and 62 subjects with DM [i.e., self-reported DM, use of diabetes medication, fasting whole blood glucose of $\geq 6.1 \mathrm{mmol} / \mathrm{L}$ (corresponding to a fasting plasma glucose of $\geq 7.0 \mathrm{mmol} / \mathrm{L}$ [29]) or $\mathrm{DM}$ according to national or local patient registers] and 108 subjects with CVD were also excluded at baseline. Finally, we excluded those with missing information for each analysis of the specific inflammatory marker. Therefore, different cohort analyses (cohort analyses 2-8) were conducted on slightly different populations when investigating different markers (Additional file 1).

In sub-analyses (sub-analyses 1-8), those who developed both DM and CVD during follow-up, regardless of order, were additionally excluded in each cohort analysis. The study population flow chart is illustrated in Additional file 1 .

All procedures performed in this study were in accordance with the ethical standards of the regional ethics committee in Lund, Sweden (LU 51/90) and with the 1964 Helsinki declaration and its later amendments or comparable ethical standard. Informed consent was obtained from all individual participants included in the study. 


\section{Baseline examinations}

After $10 \mathrm{~min}$ of rest in the supine position, blood pressure was measured using a mercury-column sphygmomanometer. Waist circumference was measured in the midpoint between the iliac crest and the lowest rib. Data on smoking habits, use of antihypertensive or antidiabetic medications were derived from a selfadministered questionnaire. Cigarette smoking status was categorized as current smokers and non-smokers.

\section{Laboratory measurements}

Fasting blood samples were drawn from the cubital vein. Blood glucose and blood cell counts were measured on the same day of blood sampling, according to standard procedures at the Department of Clinical Chemistry, University Hospital Malmö. Total leukocyte count and counts of leukocyte subtypes, including neutrophils, lymphocytes and a group of mixed cell types (monocytes, eosinophils and basophils), were measured in heparinized blood samples using a SYSMEX K1000 automated hematology analyzer (Sysmex Europe, Norderstedt, Germany). The coefficient of variations (CVs) for 20 consecutive counts of total leukocytes, neutrophils, lymphocytes, and mixed cells in one blood sample were $1.45,1.85,6.22$, and $16.1 \%$, respectively. The measurement range was $1.00 \times 10^{9}-99.9 \times 10^{9} / \mathrm{L}$ for total leukocyte count. NLR was calculated as the ratio of neutrophil and lymphocyte counts that were measured in the same blood sample. The LDL concentration was calculated according to the Friedewald's formula.

Fasting plasma samples for measuring other biomarkers were stored at $-80^{\circ} \mathrm{C}$ immediately after collection. Ceruloplasmin, alpha1-antitrypsin, orosomucoid, haptoglobin and C3 were measured by Cobas c-systems (Roche Diagnostics GmbH, Germany) [30]. The measurement range was between 0.03 and $1.40 \mathrm{~g} / \mathrm{L}$ for ceruloplasmin, 0.20 and $6.00 \mathrm{~g} / \mathrm{L}$ for alpha1-antitrypsin, 0.1 and $4.0 \mathrm{~g} / \mathrm{L}$ for orosomucoid, 0.10 and $5.70 \mathrm{~g} / \mathrm{L}$ for haptoglobin, and 0.04 and $5.00 \mathrm{~g} / \mathrm{L}$ for C3, respectively. The CVs were $<5 \%$. CRP was measured by the Tina-quant ${ }^{\circledR}$ CRP latex high sensitivity assay (Roche Diagnostics, Basel, Switzerland) on an ADVIA 1650 Chemistry System (Bayer Healthcare, NY, USA). Study samples were analysed as discrete samples and results were read in $6 \mathrm{~s}$ intervals for a $1 \mathrm{~min}$ time period following $5 \mathrm{~min}$ of incubation. The reported result was the mean value of these measurements. SuPAR was measured by an enzyme-linked immunosorbent assay suPARnostic ${ }^{\circledR}$ kit (ViroGates, Copenhagen, Denmark), with a validated range between 0.6 and $22.0 \mathrm{ng} / \mathrm{mL}$ [31]. The inter- and intra-assay CVs were 9.17 and $2.75 \%$, respectively [31].

\section{Ascertainment of endpoints}

Participants were followed from baseline examination until death, migration from Sweden, end of follow-up (December 31st, 2014), or first diagnosis of DM/CVD, whichever came first.

Information on vital status and emigration was provided by the Swedish population register, and information on incident DM [32] and CVD [33-35] was retrieved from local and national registers that have previously been described and validated [32-35]. In short, new cases of DM were identified in the Malmö $\mathrm{HbA}_{1 \mathrm{c}}$ register (MHR), the Swedish National Diabetes Register (NDR), the regional Diabetes 2000 register of the Scania region, the Swedish inpatient register, the Swedish outpatient register, and the nationwide Swedish drug prescription register. At least two independent sources confirmed the diagnosis for $74 \%$ of the cases. Since 1988, the MHR at the Department of Clinical Chemistry, Malmö University Hospital, analyzed and recorded $\mathrm{HbA}_{1 \mathrm{c}}$ samples taken in institutional and non-institutional care in the greater Malmö area. In the MHR, individuals were considered to have incident DM if they had at least two $\mathrm{HbA}_{1 \mathrm{c}}$ recordings $\geq 6.0 \%(42 \mathrm{mmol} / \mathrm{mol})$ with the Swedish Mono-S standardization system [corresponding to $7.0 \%(53 \mathrm{mmol} / \mathrm{mol})$ according to the US National Glycohemoglobin Standardization Program] during followup. In the NDR and the Diabetes 2000 register, DM was diagnosed using established diagnostic criteria (fasting glucose concentration in plasma $\geq 7.0 \mathrm{mmol} / \mathrm{L}$ with repeated tests). In the Swedish inpatient register and outpatient register, DM was diagnosed by a senior physician, while in the nationwide prescription register, a filled prescription of insulin or antidiabetic medications (ATCcode A10) was required for diagnosing DM. For CVD (i.e., coronary event or stroke), the national Swedish Hospital Discharge register, the Cause-of-Death register [33, 34] and the Stroke register of Malmö [35] were used to identify new cases of coronary event (fatal or nonfatal myocardial infarction) or stroke throughout the followup period. A coronary event was defined based on the International Classification of Diseases 9th (ICD-9) codes 410A-410X and ICD-10 code I21 or death attributable to ischemic heart disease (ICD-9 codes: 410-414; ICD-10 codes: I20-I25). Stroke was defined as ICD-9 codes 430, 431,434 or 436 , or ICD-10 codes I60, I61 or I63-64.

\section{Statistical analyses}

Participants were categorized into four groups: (1) participants who developed neither DM nor CVD during follow-up; (2) participants who developed DM but not CVD during follow-up; (3) participants who developed CVD but not DM during follow-up; (4) participants 
who developed both DM and CVD during follow-up. Because the distribution of data on CRP was skewed, a natural logarithm transformation was applied to normalize the data. The age- and sex-adjusted characteristics of the participants are presented as geometric means ( $95 \%$ confidence intervals, CIs) for continuous variables, and percentages for categorical variables. Analysis of covariance was used for continuous variables and multiple logistic regression analysis was used for categorical variables, to compare differences in baseline characteristics across the four groups as well as between groups 2 and 3 , after adjusting for age and sex. Pearsons' correlation test was performed to examine the relation between each two inflammatory markers. Incident DM and incident CVD were studied in relation to total leukocyte count, neutrophil count, lymphocyte count, mixed cell count and NLR (one biomarker at a time), based on the MDCS cohort (cohort analysis 1). Meanwhile, based on MDC-CV, the two outcomes were also studied in relation to ceruloplasmin, alpha1-antitrypsin, orosomucoid, haptoglobin, C3, CRP, and suPAR (one biomarker at a time), in another seven sets of analyses (cohort analyses 2-8). For each set of analyses, two separate analyses were conducted using either incident DM or incident CVD as the outcome. Cox regression with time-on-study as time-scale was used to estimate hazard ratios (HRs) and 95\% CIs for incident DM or CVD per one standard deviation increase in each inflammatory marker. Potential confounders in cohort analysis 1 included age, sex, waist circumference, smoking, systolic blood pressure, and use of anti-hypertensive medications. Cohort analyses 2-8 additionally included LDL-cholesterol.

We were interested in investigating whether the risk associated with each inflammatory marker was similar for the separate endpoints of DM and CVD. For this purpose, we used a competing risks approach described by Lunn and McNeil [36]. Briefly, the dataset was duplicated with two rows per individual, and was stratified on these rows. The endpoints of DM and CVD were separated into these strata. Unlike the original method [36], in this study individuals had events in both strata if they developed both DM and CVD during follow-up. An analysis was then conducted with duplicated covariates so that each covariate was allowed to have different effects in each stratum. The HRs (95\% CIs) derived from this analysis are identical to those obtained from separate Cox models fitted in the original dataset. Another analysis is then conducted, with one variable un-duplicated. This forces the effect measure for this variable to be the same for both strata. This analysis is then compared to the one with differential effects using the likelihood ratio test, with one degree of freedom, in order to derive a $p$-value for the difference in effect measures for the covariate. These steps were repeated for each inflammatory marker. Since all the subjects included in cohort analyses $2-8$ were eligible for the diagnosis of the metabolic syndrome (MetS), cohort analyses $2-8$ and the corresponding comparisons between HRs for DM versus CVD were conducted again, adjusted for age, sex, smoking, and the MetS (defined according to the NCEP-ATPIII criteria [37, 38]). Sensitivity analyses were also conducted using coronary event and stroke as separate outcomes. Furthermore, both the age and sex-adjusted analyses and multivariate analyses were repeated after excluding those who developed both DM and CVD during follow-up (group 4).

All analyses were performed using the Statistical Analysis System version 9.3 for Windows (SAS Institute Inc., Cary, NC, USA).

\section{Results}

Baseline characteristics

In MDCS $(\mathrm{n}=25,969)$, there were 3819 DM events (mean follow-up of $17.4 \pm 5.58$ years) and $4548 \mathrm{CVD}$ events (mean follow-up of $17.7 \pm 5.46$ years). 982 individuals had both DM and CVD events. In MDC-CV $(\mathrm{n}=4658)$, there were $646 \mathrm{DM}$ events (mean follow-up of 19.0 \pm 5.16 years) and 783 CVD events (mean follow-up of $19.0 \pm 5.35$ years). Among them, 151 individuals had both DM and CVD. The incidence rates of DM and CVD were 8.42 and 9.90 per 1000 person-years, respectively, in MDCS, and 7.30 and 8.83 per 1000 person-years respectively, in MDC-CV.

Baseline characteristics of participants according to DM and CVD event status during follow-up are presented in Table 1. Compared with those who developed only DM (group 2), individuals with only CVD (group 3 ) tended to be older, have lower waist circumstance, lower systolic blood pressure or less use of anti-hypertensive medications. Moreover, a larger proportion of these subjects were males or smokers. In terms of inflammatory markers, levels of lymphocyte count, C3 and CRP were lower, while levels of neutrophil count, NLR and alpha1antitrypsin were higher in group 3 , when compared with group 2.

Correlations between each two inflammatory markers are reported in Table 2. Moderate correlations were observed among most of the markers.

\section{Inflammatory markers for prediction of incident DM and CVD}

The age- and sex-adjusted HRs of biomarkers for incident DM and CVD are summarized in Table 3, and the multivariate-adjusted HRs are summarized in Table 4. After adjustment for conventional risk factors, total leukocyte count, neutrophil count, lymphocyte count, mixed cell count, orosomucoid and CRP were 
Table 1 Baseline characteristics according to incidence of diabetes (DM) and cardiovascular disease (CVD) during follow-up

\begin{tabular}{|c|c|c|c|c|c|}
\hline In MDCS $(n=25,969)$ & $\begin{array}{l}\text { Group1 without DM } \\
\text { or CVD } \\
n=18,584\end{array}$ & $\begin{array}{l}\text { Group2 incident DM } \\
\text { alone } \\
n=2837\end{array}$ & $\begin{array}{l}\text { Group3 incident CVD } \\
\text { alone } \\
\mathrm{n}=3566\end{array}$ & $\begin{array}{l}\text { Group4 incident DM } \\
\text { and CVD } \\
n=982\end{array}$ & $p$ for trend ${ }^{a}$ \\
\hline Age (years) & $57.3(57.2,57.4)^{b}$ & $57.4(57.1,57.7)^{c}$ & $61.8(61.6,62.1)^{c}$ & $60.4(59.9,60.9)$ & $<0.001$ \\
\hline Sex (male, \%) & 33.1 & $44.3^{c}$ & $52.7^{c}$ & 56.4 & $<0.001$ \\
\hline Waist circumference (cm) & $84.0(83.9,84.2)$ & $91.6(91.2,91.9)^{c}$ & $85.2(84.8,85.5)^{c}$ & $91.8(91.2,92.4)$ & $<0.001$ \\
\hline $\begin{array}{l}\text { Systolic blood pressure } \\
(\mathrm{mmHg})\end{array}$ & $139.2(138.9,139.5)$ & $145.2(144.5,145.8)^{c}$ & $143.9(143.3,144.5)^{c}$ & $149.5(148.4,150.7)$ & $<0.001$ \\
\hline Smokers (\%) & 27.4 & $27.9^{c}$ & $33.0^{c}$ & 34.2 & $<0.001$ \\
\hline $\begin{array}{l}\text { Anti-hypertensive medi- } \\
\text { cation (\%) }\end{array}$ & 12.4 & $24.2^{c}$ & $21.2^{c}$ & 31.2 & $<0.001$ \\
\hline $\begin{array}{l}\text { Total leukocyte count } \\
\left(10^{9} / \mathrm{L}\right)\end{array}$ & $6.23(6.21,6.26)$ & $6.59(6.53,6.66)$ & $6.58(6.52,6.63)$ & $6.82(6.72,6.92)$ & $<0.001$ \\
\hline Neutrophil count $\left(10^{9} / \mathrm{L}\right)$ & $3.82(3.80,3.84)$ & $4.01(3.96,4.06)^{c}$ & $4.07(4.02,4.11)^{c}$ & $4.21(4.13,4.29)$ & $<0.001$ \\
\hline $\begin{array}{l}\text { Lymphocyte count } \\
\left(10^{9} / \mathrm{L}\right)\end{array}$ & $1.90(1.89,1.91)$ & $2.04(2.02,2.06)^{c}$ & $1.98(1.95,2.00)^{c}$ & $2.05(2.01,2.09)$ & $<0.001$ \\
\hline Mixed cell count $\left(10^{9} / \mathrm{L}\right)$ & $0.517(0.514,0.520)$ & $0.541(0.534,0.549)$ & $0.537(0.530,0.543)$ & $0.558(0.545,0.571)$ & $<0.001$ \\
\hline NLR & $2.15(2.14,2.17)$ & $2.10(2.07,2.14)^{c}$ & $2.20(2.17,2.23)^{c}$ & $2.18(2.13,2.24)$ & 0.004 \\
\hline In MDC-CV ( $n=4658)$ & $\mathrm{n}=3380$ & $n=495$ & $n=632$ & $n=151$ & \\
\hline Age (years) & $56.9(56.6,57.1)$ & $56.7(56.2,57.2)$ & $60.1(59.6,60.5)$ & $59.3(58.4,60.2)$ & $<0.001$ \\
\hline Sex (male, \%) & 35.7 & $38.0^{c}$ & $52.1^{c}$ & 54.3 & $<0.001$ \\
\hline Waist circumference (cm) & $83.3(83.0,83.6)$ & $88.7(87.9,89.5)$ & $84.4(83.7,85.2)$ & $90.2(88.7,91.6)$ & 0.007 \\
\hline $\begin{array}{l}\text { Systolic blood pressure } \\
(\mathrm{mmHg})\end{array}$ & $139.2(138.6,139.8)$ & $144.3(142.7,145.8)$ & $144.2(142.9,145.6)$ & $150.3(147.5,153.1)$ & $<0.001$ \\
\hline $\begin{array}{l}\text { Low-density lipoprotein } \\
\text { cholesterol (mmol/L) }\end{array}$ & $4.12(4.09,4.16)$ & $4.30(4.21,4.38)$ & $4.19(4.11,4.27)$ & $4.33(4.17,4.48)$ & 0.112 \\
\hline Smokers (\%) & 21.5 & $22.2^{c}$ & $29.1^{c}$ & 27.8 & $<0.001$ \\
\hline $\begin{array}{l}\text { Anti-hypertensive medica- } \\
\text { tion (\%) }\end{array}$ & 11.0 & $21.2^{c}$ & $18.7^{c}$ & 25.2 & $<0.001$ \\
\hline $\begin{array}{l}\text { Ceruloplasmin (g/L) (miss- } \\
\text { ing }=536)\end{array}$ & $0.500(0.496,0.505)$ & $0.503(0.492,0.514)$ & $0.513(0.503,0.523)$ & $0.516(0.496,0.537)$ & 0.020 \\
\hline $\begin{array}{l}\text { Alpha1-antitrypsin (g/L) } \\
\quad(\text { missing }=359)\end{array}$ & $1.20(1.19,1.21)$ & $1.20(1.17,1.22)^{c}$ & $1.24(1.22,1.26)^{c}$ & $1.24(1.19,1.29)$ & 0.002 \\
\hline $\begin{array}{l}\text { Orosomucoid (g/L) (miss- } \\
\text { ing }=336 \text { ) }\end{array}$ & $0.693(0.685,0.700)$ & $0.752(0.732,0.771)$ & $0.731(0.714,0.748)$ & $0.763(0.728,0.797)$ & $<0.001$ \\
\hline $\begin{array}{l}\text { Haptoglobin (g/L) (miss- } \\
\text { ing =667) }\end{array}$ & $1.28(1.26,1.30)$ & $1.36(1.31,1.42)$ & $1.34(1.29,1.39)$ & $1.46(1.36,1.55)$ & 0.020 \\
\hline C3 (g/L) (missing = 289) & $1.50(1.49,1.51)$ & $1.66(1.63,1.69)^{c}$ & $1.54(1.52,1.57)^{c}$ & $1.68(1.62,1.73)$ & 0.004 \\
\hline $\begin{array}{l}\mathrm{CRP}(\mathrm{mg} / \mathrm{L})(\mathrm{miss}- \\
\text { ing }=187)\end{array}$ & $2.25(2.1,2.39)$ & $3.09(2.71,3.47)^{c}$ & $2.66(2.31,3.00)^{c}$ & $3.75(3.05,4.46)$ & 0.030 \\
\hline $\begin{array}{l}\text { SuPAR }(\mathrm{ng} / \mathrm{mL}) \text { (miss- } \\
\text { ing }=149)\end{array}$ & $2.93(2.9,2.96)$ & $3.04(2.96,3.12)$ & $3.16(3.08,3.23)$ & $3.07(2.92,3.22)$ & $<0.001$ \\
\hline
\end{tabular}

NLR neutrophil to lymphocyte ratio, CRP C-reactive protein, SUPAR soluble urokinase plasminogen activator receptor

a Analysis of covariance or multiple logistic regression analysis, adjusted for age and sex

b Geometric mean (95\% confidence interval) (all such values)

c Significant difference was found when participants with incident DM alone were compared with those with CVD alone

associated with an increased risk of both DM and CVD. In addition, NLR, ceruloplasmin, alpha1-antitrypsin, and SuPAR predicted increased risk of CVD but not $\mathrm{DM}$, while haptoglobin and $\mathrm{C} 3$ predicted increased risk of DM but not CVD.
Inflammatory profiles for DM and CVD were generally consistent in secondary analyses excluding those who developed both DM and CVD (Additional files 2, 3). However, the association of haptoglobin with DM that was initially observed in Table 4 was statistically 
Table 2 Pearson correlations between every two inflammatory markers

\begin{tabular}{|c|c|c|c|c|c|c|c|}
\hline In MDCC $(n=25,969)$ & $\begin{array}{l}\text { Total leukocyte } \\
\text { count }\end{array}$ & $\begin{array}{l}\text { Neutrophil } \\
\text { count }\end{array}$ & Lymphocyte count & Mixed cell count & NLR & & \\
\hline Neutrophil count & 0.91 & - & - & - & - & & \\
\hline Lymphocyte count & 0.61 & 0.25 & - & - & - & & \\
\hline Mixed cell count & 0.45 & 0.27 & 0.30 & - & - & & \\
\hline NLR & 0.31 & 0.62 & -0.48 & - & - & & \\
\hline In MDCC $(n=3630)$ & Ceruloplasmin & $\begin{array}{l}\text { Alpha1- } \\
\text { antitrypsin }\end{array}$ & Orosomucoid & Haptoglobin & $\mathrm{C3}$ & CRP & SUPAR \\
\hline Alpha1-antitrypsin & 0.52 & - & - & - & - & - & - \\
\hline Orosomucoid & 0.45 & 0.40 & - & - & - & - & - \\
\hline Haptoglobin & 0.43 & 0.41 & 0.60 & - & - & - & - \\
\hline Complement C3 & 0.52 & 0.41 & 0.60 & 0.51 & - & - & - \\
\hline CRP & 0.38 & 0.27 & 0.52 & 0.44 & 0.40 & - & - \\
\hline SUPAR & 0.13 & 0.17 & 0.22 & 0.19 & 0.08 & 0.23 & - \\
\hline Total leukocyte count & 0.07 & 0.12 & 0.17 & 0.20 & 0.09 & 0.20 & 0.21 \\
\hline Neutrophil count & 0.05 & 0.12 & 0.16 & 0.17 & 0.06 & 0.16 & 0.18 \\
\hline Lymphocyte count & 0.06 & - & 0.07 & 0.14 & 0.11 & 0.14 & 0.14 \\
\hline Mixed cell count & - & 0.06 & 0.12 & 0.12 & 0.11 & 0.14 & 0.13 \\
\hline NLR & - & 0.10 & 0.10 & 0.07 & - & 0.06 & 0.09 \\
\hline
\end{tabular}

NLR neutrophil to lymphocyte ratio, CRP C-reactive protein, SUPAR soluble urokinase plasminogen activator receptor $r>0.05$ is statistically significant, $p<0.01$

Table 3 Comparison of risk of diabetes and cardiovascular disease in relation to inflammatory markers (age, sexadjusted)

\begin{tabular}{|c|c|c|c|c|c|c|c|c|}
\hline \multirow[t]{2}{*}{ Inflammatory markers } & \multirow[t]{2}{*}{ No. of subjects } & \multicolumn{3}{|l|}{ Diabetes } & \multicolumn{3}{|c|}{ Cardiovascular disease } & \multirow{2}{*}{$\begin{array}{l}p \text { value } \\
\text { for equal } \\
\text { associations }\end{array}$} \\
\hline & & Incidence & $\operatorname{HR}(95 \% \mathrm{Cl})^{\mathrm{a}}$ & $p^{\mathbf{b}}$ & Incidence & $\mathrm{HR}(95 \% \mathrm{Cl})^{\mathrm{a}}$ & $p^{\mathbf{b}}$ & \\
\hline \multicolumn{9}{|l|}{ In MDCS } \\
\hline Total leukocyte count & 25,969 & 3819 & $1.249(1.214,1.285)$ & $<0.001$ & 4548 & $1.235(1.202,1.269)$ & $<0.001$ & 0.572 \\
\hline Neutrophil count & 25,969 & 3819 & $1.182(1.148,1.216)$ & $<0.001$ & 4548 & $1.209(1.177,1.242)$ & $<0.001$ & 0.245 \\
\hline Lymphocyte count & 25,969 & 3819 & $1.171(1.147,1.196)$ & $<0.001$ & 4548 & $1.105(1.081,1.130)$ & $<0.001$ & $<0.001$ \\
\hline Mixed cell count & 25,969 & 3819 & $1.150(1.116,1.185)$ & $<0.001$ & 4548 & $1.109(1.079,1.140)$ & $<0.001$ & 0.080 \\
\hline NLR & 25,969 & 3819 & $0.981(0.949,1.014)$ & 0.265 & 4548 & $1.058(1.030,1.088)$ & $<0.001$ & $<0.001$ \\
\hline \multicolumn{9}{|l|}{ In MDC-CV } \\
\hline Ceruloplasmin & 4122 & 543 & $1.056(0.967,1.153)$ & 0.225 & 678 & $1.123(1.040,1.213)$ & 0.003 & 0.300 \\
\hline Alpha1-antitrypsin & 4299 & 583 & $1.042(0.959,1.133)$ & 0.330 & 709 & $1.167(1.086,1.254)$ & $<0.001$ & 0.044 \\
\hline Orosomucoid & 4322 & 591 & $1.290(1.203,1.384)$ & $<0.001$ & 716 & $1.185(1.109,1.267)$ & $<0.001$ & 0.087 \\
\hline Haptoglobin & 3991 & 520 & $1.235(1.138,1.339)$ & $<0.001$ & 651 & $1.171(1.087,1.262)$ & $<0.001$ & 0.351 \\
\hline C3 & 4369 & 598 & $1.452(1.362,1.547)$ & $<0.001$ & 722 & $1.151(1.075,1.232)$ & $<0.001$ & $<0.001$ \\
\hline CRP & 4471 & 615 & $1.413(1.306,1.529)$ & $<0.001$ & 729 & $1.244(1.157,1.337)$ & $<0.001$ & 0.020 \\
\hline SUPAR & 4509 & 618 & $1.149(1.068,1.237)$ & $<0.001$ & 751 & $1.261(1.184,1.342)$ & $<0.001$ & 0.060 \\
\hline
\end{tabular}

HR hazard ratio, Cl confidence interval, NLR neutrophil to lymphocyte ratio, CRP C-reactive protein, SUPAR soluble urokinase plasminogen activator receptor

${ }^{\text {a }}$ Age- and sex-adjusted hazard ratios and $95 \%$ confidence intervals, per 1 standard deviation (all such values)

${ }^{b}$ Analysis by Cox proportional hazards model

c $p$ value associated with the null hypothesis that this variable has the same association with diabetes and cardiovascular disease, with all other effects being different; tests for all variables have $1 \mathrm{df}$ 
Table 4 Comparison of risk of diabetes and cardiovascular disease in relation to inflammatory markers (multivariate analysis)

\begin{tabular}{|c|c|c|c|c|c|c|c|c|}
\hline \multirow[t]{2}{*}{ Inflammatory markers } & \multirow[t]{2}{*}{ No. of subjects } & \multicolumn{3}{|l|}{ Diabetes } & \multicolumn{3}{|c|}{ Cardiovascular disease } & \multirow{2}{*}{$\begin{array}{l}p \text { value } \\
\text { for equal } \\
\text { associations }\end{array}$} \\
\hline & & Incidence & $\mathrm{HR}(95 \% \mathrm{Cl})^{\mathrm{a}}$ & $p^{b}$ & Incidence & $\mathrm{HR}(95 \% \mathrm{Cl})^{\mathrm{a}}$ & $p^{b}$ & \\
\hline \multicolumn{9}{|l|}{$\ln \mathrm{MDCS}^{\mathrm{d}}$} \\
\hline Total leukocyte count & 25,969 & 3819 & $1.118(1.082,1.154)$ & $<0.001$ & 4548 & $1.114(1.081,1.148)$ & $<0.001$ & 0.888 \\
\hline Neutrophil count & 25,969 & 3819 & $1.086(1.052,1.121)$ & $<0.001$ & 4548 & $1.108(1.076,1.140)$ & $<0.001$ & 0.365 \\
\hline Lymphocyte count & 25,969 & 3819 & $1.092(1.060,1.124)$ & $<0.001$ & 4548 & $1.040(1.012,1.070)$ & $<0.001$ & 0.020 \\
\hline Mixed cell count & 25,969 & 3819 & $1.054(1.021,1.087)$ & $<0.001$ & 4548 & $1.050(1.020,1.080)$ & $<0.001$ & 0.862 \\
\hline NLR & 25,969 & 3819 & $0.998(0.966,1.032)$ & 0.929 & 4548 & $1.049(1.020,1.078)$ & $<0.001$ & 0.025 \\
\hline \multicolumn{9}{|l|}{ In $\mathrm{MDC}-\mathrm{CV}^{\mathrm{e}}$} \\
\hline Ceruloplasmin & 4122 & 543 & $1.002(0.912,1.100)$ & 0.971 & 678 & $1.087(1.002,1.179)$ & 0.045 & 0.197 \\
\hline Alpha1-antitrypsin & 4299 & 583 & $1.025(0.942,1.116)$ & 0.565 & 709 & $1.113(1.033,1.199)$ & 0.005 & 0.154 \\
\hline Orosomucoid & 4322 & 591 & $1.118(1.032,1.211)$ & 0.006 & 716 & $1.088(1.011,1.171)$ & 0.024 & 0.626 \\
\hline Haptoglobin & 3991 & 520 & $1.110(1.017,1.210)$ & 0.019 & 651 & $1.061(0.979,1.149)$ & 0.149 & 0.455 \\
\hline C3 & 4369 & 598 & $1.250(1.160,1.347)$ & $<0.001$ & 722 & $1.076(0.997,1.161)$ & 0.059 & 0.006 \\
\hline CRP & 4471 & 615 & $1.174(1.076,1.280)$ & $<0.001$ & 729 & $1.116(1.033,1.206)$ & 0.005 & 0.396 \\
\hline SUPAR & 4509 & 618 & $1.041(0.956,1.133)$ & 0.360 & 751 & $1.137(1.059,1.221)$ & $<0.001$ & 0.117 \\
\hline
\end{tabular}

$H R$ hazard ratio, $\mathrm{Cl}$ confidence interval, NLR neutrophil to lymphocyte ratio, CRP C-reactive protein, SUPAR soluble urokinase plasminogen activator receptor

a Adjusted hazard ratios and 95\% confidence intervals, per 1 standard deviation (all such values)

b Analysis by Cox proportional hazards model

c $p$ value associated with the null hypothesis that this variable has the same association with diabetes and cardiovascular disease, with all other effects being different; tests for all variables have $1 \mathrm{df}$

d Adjusted for age, sex, waist circumference, smoking, systolic blood pressure, and anti-hypertensive drug medication

e Adjusted for age, sex, waist circumference, smoking, systolic blood pressure, low-density lipoprotein, and anti-hypertensive drug medication

nonsignificant in this sub-group (Additional file 3, fully adjusted model).

\section{Comparisons of inflammatory markers for incident DM and CVD}

The analyses of differential effects between DM and CVD outcomes for each specific inflammatory marker are presented in Tables 3 and 4. After adjusting for age and sex (Table 3), several markers showed differential associations with DM versus CVD. After adjusting for other potential confounders (Table 4), only the associations of lymphocyte count, NLR and C3 showed significantly different effects for DM versus CVD ( $p$ value for equal associations $=0.020,=0.025$ and $=0.006$, respectively). Both lymphocyte count and $\mathrm{C} 3$ had stronger associations with risk of DM compared with CVD, and the predictive value of C3 for DM was considerably stronger than for CVD. By contrast, NLR was associated with an increased risk of CVD but was not associated with DM. In sensitivity analyses, results were substantially unchanged when age, sex, smoking, and the MetS were adjusted for in multivariate analyses (data not shown). Likewise, consistent results were observed after excluding those who developed both DM and CVD during follow-up (Additional file 3, fully adjusted model). The additional analyses using coronary event and stroke as separate outcomes revealed that the inequal associations of NLR with DM versus CVD were mainly contributed by coronary events, while the inequal associations of lymphocyte count and C3 with DM versus CVD were mainly contributed by stroke events (data not shown).

\section{Discussion}

To our knowledge, this is the first cohort study comparing the predictive values of different inflammatory markers for the risk of DM versus CVD. Overall, the results indicated substantial similarities in the inflammatory profiles associated with DM and CVD. Lymphocyte count, NLR and $\mathrm{C} 3$ were associated differently with DM versus CVD. In particular, C3 showed a remarkable difference in its association with DM compared to CVD. Taken together, the results suggest that there is an inflammatory 'common soil' for DM and CVD, but there are also important differences.

Previous genetic studies have supported an overlap between the pathogenesis of DM and CVD [5, 6]. Traditional CVD risk factors, including inflammation and endothelial dysfunction, have also been found to be positively associated with incident DM $[2,3]$. The MetS predisposes to both DM and CVD, which are considered 
to be particularly triggered by IR and atherosclerosis, respectively [6]. These two disorders have been shown by gene set enrichment analysis to have shared dysregulated pathways, many of which are involved in inflammatory responses [6]. Nevertheless, it is noteworthy that the MetS was differently associated with DM versus CVD [9-11]. In addition, acute-phase proteins exhibit different predictive ability for changes in insulin secretion, insulin sensitivity, and cardiometabolic traits, indicating that different inflammatory cytokines capture distinct aspects of inflammation [15]. In the recently reported Canakinumab Anti-inflammatory Thrombosis Outcome Study (CANTOS), canakinumab, an inflammation inhibitor targeting at interleukin-1ß, showed significant effect on cardiovascular events [14]. However, despite marked reductions in CRP and interleukin-1, it did not reduce incident DM [12], suggesting divergence of inflammatory pathways in CVD and DM. Therefore, specific anti-inflammatory targets for therapeutic interventions need to be recognized for individuals with DM and CVD, respectively [13].

The relationship between $\mathrm{C} 3$ and risk of DM in the general population supports the conclusion from other prospective studies $[24,29,39,40]$ demonstrating that elevated C3 levels are associated with an increased risk of IR, prediabetes and DM. In addition, elevated C3 concentration was shown to be a stronger predictor of DM than multiple other acute-phase proteins [24, 29]. The C3-dependent immune response may contribute to destruction of pancreatic islets and hepatic dysfunction $[41,42]$, both of which are important risk factors for hyperglycemia $[7,43]$. Another possible pathophysiological link is that the proteolytic fragments of C3, C3a and $\mathrm{C} 5 \mathrm{a}$, may mediate adipose tissue inflammation and IR $[44,45]$, and thus facilitate DM development [7]. Prospective studies of $\mathrm{C} 3$ and incident CVD are relatively few, especially in apparently healthy subjects [46, 47]. Muscari et al. have demonstrated an increased risk of CVD in men with high C3 levels, but these analyses were only age-adjusted [46]. Engström et al. have confirmed this finding, but also noted that the observed association was completely attenuated and non-significant after adjusting for potential confounders including baseline DM [47]. In line with these studies, we observed a C3-CVD association in models adjusted for age and sex, but not in fully adjusted models. It has been suggested that, in DM, the interaction between $\mathrm{C} 3$ and fibrinogen may be responsible for impaired fibrinolysis and subsequent CVD risk [48].

Total and differential leukocyte counts are traditional markers of subclinical inflammation and their associations with risk of DM and CVD have been widely reported in epidemiological studies [17-23]. In accordance with previous findings, we demonstrated that, among the major leukocyte subtypes, the strongest risk prediction for CVD was given by neutrophil count [17, $18,20-22]$, and the strongest risk prediction for DM was given by lymphocyte count $[19,23]$. Neutrophil infiltration has been observed both in atherosclerosis in the aorta of atherosclerotic mice [49] and in culprit lesions in patients with acute coronary syndromes [50]. Neutrophils may mediate cardiovascular anomalies by interacting with endothelium and platelets [49, 51], leading to plaque destabilization [52]. As for DM, the predictive ability of lymphocyte count was the strongest, but still rather similar to that of neutrophil count [23]. Both neutrophils and lymphocytes have been found to be critical to obesity-associated adipose tissue inflammation, which subsequently contributes to IR and DM [53-55]. In addition to previous evidence, we further demonstrated that neutrophil count was similarly associated with DM and with CVD while the predictive ability of lymphocyte count for DM was superior to that for CVD. NLR shows the combined effect of neutrophil count and lymphocyte count. Whereas its prognostic value in CVD has been widely discussed $[18,56]$, controversy has remained regarding whether NLR is an efficient predictor for DM $[19,57]$. In the present study, NLR was found to be predictive for CVD but not DM. Similarly, NLR was not associated with IR or adiposity in previous studies [19, $58,59]$. It is noteworthy that despite a strong association of lymphocyte count with DM, the role of lymphocyte count in CVD seems to be weak or even inverse [17, 18, 20-22]. The association of NLR with CVD may be driven by neutrophil-related processes, rather than by adiposity or IR.

This study used a large sample with long-term followup. Outcome data were retrieved from validated hospital registers with national coverage [32-35], which should reduce information bias. The competing risks analyses were conducted before and after excluding those with both incident DM and incident CVD, which helps to distinguish between the shared and specific markers for DM and CVD. Our study is limited by lack of information on other potential inflammatory markers. In addition, DM types were not distinguished. However, all participants were middle-aged adults. Because people with type $1 \mathrm{DM}$ usually show symptoms in early life, they should have been thoroughly excluded at baseline as prevalent cases. Therefore, all cases of incident DM in this study were very likely to be type $2 \mathrm{DM}$.

\section{Conclusions}

There are many similarities, but also important differences in the associations of inflammatory markers with DM versus CVD. Most importantly, C3 was an efficient and highly specific predictor of DM. In addition, 
lymphocyte count showed superior predictive value for DM than for CVD, while NLR was a specific and moderate predictor of CVD, but not for DM. Our results may help discriminate between individuals at elevated risk of DM and those at elevated risk of CVD, which is a prerequisite for targeted therapies.

\section{Additional files}

Additional file 1. Study population flow chart. Figure S1. MDCS the Malmö Diet and Cancer study, MDC-CV the Malmö Diet and Cancer Cardiovascular cohort study, CVD cardiovascular disease, LDL low-density lipoprotein, CRP C-reactive protein, SUPAR soluble urokinase plasminogen activator receptor.

Additional file 2. Comparison of risk of diabetes and cardiovascular disease in relation to inflammatory markers (age, sex-adjusted analysis excluding those who developed both diabetes and cardiovascular disease).

Additional file 3. Comparison of risk of diabetes and cardiovascular disease in relation to inflammatory markers (multivariate analysis excluding those who developed both diabetes and cardiovascular disease).

\section{Abbreviations}

CANTOS: Canakinumab Anti-inflammatory Thrombosis Outcome Study; Cl: confidence interval; CRP: C-reactive protein; CV: coefficient of variation; CVD: cardiovascular disease; DM: diabetes mellitus; HR: hazard ratio; IR: insulin resistance; ICD: International Classification of Diseases; LDL: low-density lipoprotein; MDCS: Malmö Diet and Cancer study; MDC-CV: Malmö Diet and Cancer Cardiovascular cohort study; MetS: metabolic syndrome; MHR: Malmö HbA1c register; NDR: National Diabetes Register; NLR: neutrophil to lymphocyte ratio; SUPAR: soluble urokinase plasminogen activator receptor.

\section{Authors' contributions}

XB and GE conceived the study. XB analyzed the data and drafted the paper. All authors were involved in the interpretation of the data, contributed towards critical revision of the manuscript. All authors read and approved the final manuscript.

\section{Author details}

${ }^{1}$ Nutritional Epidemiology Institute and School of Public Health, Tianjin Medical University, Tianjin, China. ${ }^{2}$ Department of Clinical Sciences, Lund University, CRC 60:13, Jan Waldenströms gata 35, 20502 Malmö, Sweden.

\section{Acknowledgements}

The authors gratefully acknowledge the participants of the study and all medical and nursing staff of University Hospital. We also would like to acknowledge the information provided by the National Diabetes Register of Sweden, the Malmö HbA1c register, the Diabetes register 2000, and the registers provided by the Swedish Board of Health and Welfare.

\section{Competing interests}

The authors declare that they have no competing interests.

\section{Availability of data and materials}

The data that support the findings of this study are available from Lund University, but restrictions apply to the availability of these data, which were used under license for the current study, and so are not publicly available. Data are however available from the authors upon reasonable request and with permission of Lund University.

\section{Consent for publication}

Not applicable.

\section{Ethics approval and consent to participate}

All procedures performed in this study was in accordance with the ethical standards of the regional ethics committee in Lund, Sweden (LU 51/90) and with the 1964 Helsinki declaration and its later amendments or comparable ethical standard. Informed consent was obtained from all individual participants included in the study.

\section{Funding}

The study was funded by the Medical Research Council of Sweden (Grant No. 2014-2265), the Swedish Heart-Lung Foundation (Grant No. 2016-0315), the Region Skåne County Council, the Ernhold Lundstrom Foundation and the China Scholarship Council (Grant No. 201706940044). The funders had no role in study design, data collection and analysis, decision to publish, or preparation of the manuscript.

\section{Publisher's Note}

Springer Nature remains neutral with regard to jurisdictional claims in published maps and institutional affiliations.

Received: 5 April 2018 Accepted: 6 June 2018

Published online: 12 June 2018

\section{References}

1. Collaboration Emerging Risk Factors. Diabetes mellitus, fasting blood glucose concentration, and risk of vascular disease: a collaborative metaanalysis of 102 prospective studies. Lancet. 2010;375(9733):2215-22.

2. D'Agostino RB Jr, Hamman RF, Karter AJ, Mykkanen L, Wagenknecht LE, Haffner SM. Insulin Resistance Atherosclerosis Study I. Cardiovascular disease risk factors predict the development of type 2 diabetes: the insulin resistance atherosclerosis study. Diabetes Care. 2004;27(9):2234-40.

3. Odegaard AO, Jacobs DR Jr, Sanchez OA, Goff DC Jr, Reiner AP, Gross MD. Oxidative stress, inflammation, endothelial dysfunction and incidence of type 2 diabetes. Cardiovasc Diabetol. 2016;15:51.

4. Stern MP. Diabetes and cardiovascular disease. The "common soil" hypothesis. Diabetes. 1995;44(4):369-74.

5. Shu L, Chan KHK, Zhang G, Huan T, Kurt Z, Zhao Y, Codoni V, Tregouet DA, Cardiogenics C, Yang J, et al. Shared genetic regulatory networks for cardiovascular disease and type 2 diabetes in multiple populations of diverse ethnicities in the United States. PLoS Genet. 2017;13(9):e1007040.

6. Moreno-Viedma V, Amor M, Sarabi A, Bilban M, Staffler G, Zeyda M, Stulnig TM. Common dysregulated pathways in obese adipose tissue and atherosclerosis. Cardiovasc Diabetol. 2016;15(1):120.

7. Donath MY, Shoelson SE. Type 2 diabetes as an inflammatory disease. Nat Rev Immunol. 2011:11(2):98-107.

8. Ruparelia N, Chai JT, Fisher EA, Choudhury RP. Inflammatory processes in cardiovascular disease: a route to targeted therapies. Nat Rev Cardiol. 2017;14(3):133-44.

9. Alberti KG, Eckel RH, Grundy SM, Zimmet PZ, Cleeman Jl, Donato KA, Fruchart JC, James WP, Loria CM, Smith SC Jr, et al. Harmonizing the metabolic syndrome: a joint interim statement of the International Diabetes Federation Task Force on Epidemiology and Prevention; National Heart, Lung, and Blood Institute; American Heart Association; World Heart Federation; International Atherosclerosis Society; and International Association for the Study of Obesity. Circulation. 2009;120(16):1640-5.

10. Das UN. Metabolic syndrome $X$ : an inflammatory condition? Curr Hypertens Rep. 2004;6(1):66-73.

11. Sattar N, McConnachie A, Shaper AG, Blauw GJ, Buckley BM, de Craen AJ, Ford I, Forouhi NG, Freeman DJ, Jukema JW, et al. Can metabolic syndrome usefully predict cardiovascular disease and diabetes? Outcome data from two prospective studies. Lancet. 2008;371(9628):1927-35.

12. Everett BM, Donath MY, Pradhan AD, Thuren T, Pais P, Nicolau JC, Glynn RJ, Libby P, Ridker PM. Anti-inflammatory therapy with canakinumab for the prevention and management of diabetes. J Am Coll Cardiol. 2018;71:2392-401.

13. Tenenbaum A, Fisman EZ. Mirroring the CANTOS revolution: is antiinflammatory therapy for diabetes just around the corner? Cardiovasc Diabetol. 2017;16(1):91. 
14. Ridker PM, Everett BM, Thuren T, MacFadyen JG, Chang WH, Ballantyne C, Fonseca F, Nicolau J, Koenig W, Anker SD, et al. Antiinflammatory therapy with canakinumab for atherosclerotic disease. N Engl J Med. 2017;377(12):1119-31.

15. Fizelova M, Jauhiainen R, Kangas AJ, Soininen P, Ala-Korpela M, Kuusisto J, Laakso M, Stancakova A. Differential associations of inflammatory markers with insulin sensitivity and secretion: the prospective METSIM study. J Clin Endocrinol Metab. 2017;102(9):3600-9.

16. Greenberg AS, Obin MS. Obesity and the role of adipose tissue in inflammation and metabolism. Am J Clin Nutr. 2006;83(2):461S-5S.

17. Gillum RF, Mussolino ME, Madans JH. Counts of neutrophils, lymphocytes, and monocytes, cause-specific mortality and coronary heart disease: the NHANES-I epidemiologic follow-up study. Ann Epidemiol. 2005;15(4):266-71.

18. Horne BD, Anderson JL, John JM, Weaver A, Bair TL, Jensen KR, Renlund DG, Muhlestein JB. Intermountain Heart Collaborative Study G. Which white blood cell subtypes predict increased cardiovascular risk? J Am Coll Cardiol. 2005:45(10):1638-43.

19. Lorenzo C, Hanley AJ, Haffner SM. Differential white cell count and incident type 2 diabetes: the insulin resistance atherosclerosis study. Diabetologia. 2014;57(1):83-92.

20. Madjid M, Awan I, Willerson JT, Casscells SW. Leukocyte count and coronary heart disease: implications for risk assessment. J Am Coll Cardiol. 2004:44(10):1945-56.

21. Rana JS, Boekholdt SM, Ridker PM, Jukema JW, Luben R, Bingham SA, Day NE, Wareham NJ, Kastelein JJ, Khaw KT. Differential leucocyte count and the risk of future coronary artery disease in healthy men and women: the EPIC-Norfolk Prospective Population Study. J Intern Med. 2007;262(6):678-89.

22. Wheeler JG, Mussolino ME, Gillum RF, Danesh J. Associations between differential leucocyte count and incident coronary heart disease: 1764 incident cases from seven prospective studies of 30,374 individuals. Eur Heart J. 2004;25(15):1287-92.

23. Zhang H, Yang Z, Zhang W, Niu Y, Li X, Qin L, Su Q. White blood cell subtypes and risk of type 2 diabetes. J Diabetes Complications. 2017;31(1):31-7.

24. Engström G, Hedblad B, Eriksson KF, Janzon L, Lindgarde F. Complement C3 is a risk factor for the development of diabetes: a population-based cohort study. Diabetes. 2005;54(2):570-5.

25. Muscari A, Antonelli S, Bianchi G, Cavrini G, Dapporto S, Ligabue A, Ludovico C, Magalotti D, Poggiopollini G, Zoli M, et al. Serum C3 is a stronger inflammatory marker of insulin resistance than C-reactive protein, leukocyte count, and erythrocyte sedimentation rate: comparison study in an elderly population. Diabetes Care. 2007;30(9):2362-8.

26. Manjer J, Carlsson S, Elmstahl S, Gullberg B, Janzon L, Lindstrom M, Mattisson I, Berglund G. The Malmo Diet and Cancer Study: representativity, cancer incidence and mortality in participants and non-participants. Eur 」 Cancer Prev. 2001;10(6):489-99.

27. Zia E, Melander O, Bjorkbacka H, Hedblad B, Engström G. Total and differential leucocyte counts in relation to incidence of stroke subtypes and mortality: a prospective cohort study. J Intern Med. 2012;272(3):298-304.

28. Hedblad B, Nilsson P, Janzon L, Berglund G. Relation between insulin resistance and carotid intima-media thickness and stenosis in nondiabetic subjects. Results from a cross-sectional study in Malmo, Sweden. Diabet Med. 2000;17(4):299-307.

29. Borne Y, Muhammad IF, Lores-Motta L, Hedblad B, Nilsson PM, Melander $\mathrm{O}$, de Jong EK, Blom AM, den Hollander Al, Engström G. Complement C3 associates with incidence of diabetes, but no evidence of a causal relationship. J Clin Endocrinol Metab. 2017;102(12):4477-85.

30. Muhammad IF, Borne Y, Hedblad B, Nilsson PM, Persson M, Engström G. Acute-phase proteins and incidence of diabetes: a population-based cohort study. Acta Diabetol. 2016;53(6):981-9.

31. Eugen-Olsen J, Andersen O, Linneberg A, Ladelund S, Hansen TW, Langkilde A, Petersen J, Pielak T, Moller LN, Jeppesen J, et al. Circulating soluble urokinase plasminogen activator receptor predicts cancer, cardiovascular disease, diabetes and mortality in the general population. J Intern Med. 2010;268(3):296-308.

32. Enhorning S, Sjogren M, Hedblad B, Nilsson PM, Struck J, Melander O. Genetic vasopressin $1 \mathrm{~b}$ receptor variance in overweight and diabetes mellitus. Eur J Endocrinol. 2016;174(1):69-75.
33. Hammar N, Alfredsson L, Rosen M, Spetz CL, Kahan T, Ysberg AS. A national record linkage to study acute myocardial infarction incidence and case fatality in Sweden. Int J Epidemiol. 2001;30(Suppl 1):S30-4.

34. Delpierre C, Lauwers-Cances V, Datta GD, Lang T, Berkman L. Using self-rated health for analysing social inequalities in health: a risk for underestimating the gap between socioeconomic groups? J Epidemiol Community Health. 2009;63(6):426-32.

35. Khan FA, Zia E, Janzon L, Engström G. Incidence of stroke and stroke subtypes in Malmo, Sweden, 1990-2000: marked differences between groups defined by birth country. Stroke. 2004;35(9):2054-8.

36. Lunn M, McNeil D. Applying Cox regression to competing risks. Biometrics. 1995:51(2):524-32.

37. Grundy SM, Cleeman JI, Daniels SR, Donato KA, Eckel RH, Franklin BA, Gordon DJ, Krauss RM, Savage PJ, Smith SC Jr, et al. Diagnosis and management of the metabolic syndrome: an American Heart Association/ National Heart, Lung, and Blood Institute Scientific Statement. Circulation. 2005;112(17):2735-52.

38. Nilsson PM, Engström G, Hedblad B. The metabolic syndrome and incidence of cardiovascular disease in non-diabetic subjects-a population-based study comparing three different definitions. Diabet Med. 2007;24(5):464-72.

39. Wlazlo N, van Greevenbroek MM, Ferreira I, Feskens EJ, van der Kallen CJ, Schalkwijk CG, Bravenboer B, Stehouwer CD. Complement factor 3 is associated with insulin resistance and with incident type 2 diabetes over a 7-year follow-up period: the CODAM Study. Diabetes Care. 2014;37(7):1900-9.

40. Bao X, Xia Y, Zhang Q, Wu HM, Du HM, Liu L, Wang CJ, Shi HB, Guo XY, Liu $X$, et al. Elevated serum complement $C 3$ levels are related to the development of prediabetes in an adult population: the Tianjin Chronic Low-Grade Systematic Inflammation and Health Cohort Study. Diabet Med. 2016:33(4):446-53.

41. Gao X, Liu H, Ding G, Wang Z, Fu H, Ni Z, Ma J, Liu F, Fu Z. Complement C3 deficiency prevent against the onset of streptozotocin-induced autoimmune diabetes involving expansion of regulatory T cells. Clin Immunol. 2011;140(3):236-43.

42. Bykov I, Jauhiainen M, Olkkonen VM, Saarikoski ST, Ehnholm C, Junnikkala S, Vakeva A, Lindros KO, Meri S. Hepatic gene expression and lipid parameters in complement $\mathrm{C} 3(-/-)$ mice that do not develop ethanolinduced steatosis. J Hepatol. 2007;46(5):907-14.

43. Nguyen QM, Srinivasan SR, Xu JH, Chen W, Hassig S, Rice J, Berenson GS. Elevated liver function enzymes are related to the development of prediabetes and type 2 diabetes in younger adults: the Bogalusa Heart Study. Diabetes Care. 2011;34(12):2603-7.

44. Mamane Y, Chung Chan C, Lavallee G, Morin N, Xu LJ, Huang J, Gordon R, Thomas W, Lamb J, Schadt EE, et al. The C3a anaphylatoxin receptor is a key mediator of insulin resistance and functions by modulating adipose tissue macrophage infiltration and activation. Diabetes. 2009;58(9):2006-17.

45. Phieler J, Chung KJ, Chatzigeorgiou A, Klotzsche-von Ameln A, Garcia-Martin R, Sprott D, Moisidou M, Tzanavari T, Ludwig B, Baraban $\mathrm{E}$, et al. The complement anaphylatoxin $\mathrm{C} 5 \mathrm{a}$ receptor contributes to obese adipose tissue inflammation and insulin resistance. J Immunol. 2013;191(8):4367-74

46. Muscari A, Bozzoli C, Puddu GM, Sangiorgi Z, Dormi A, Rovinetti C, Descovich GC, Puddu P. Association of serum C3 levels with the risk of myocardial infarction. Am J Med. 1995;98(4):357-64.

47. Engström G, Hedblad B, Janzon L, Lindgarde F. Complement C3 and C4 in plasma and incidence of myocardial infarction and stroke: a populationbased cohort study. Eur J Cardiovasc Prev Rehabil. 2007;14(3):392-7.

48. King R, Tiede C, Simmons K, Fishwick C, Tomlinson D, Ajjan R. Inhibition of complement $\mathrm{C} 3$ and fibrinogen interaction: a potential novel therapeutic target to reduce cardiovascular disease in diabetes. Lancet. 2015;385(Suppl 1):S57.

49. Eriksson EE, Xie X, Werr J, Thoren P, Lindbom L. Direct viewing of atherosclerosis in vivo: plaque invasion by leukocytes is initiated by the endothelial selectins. FASEB J. 2001;15(7):1149-57.

50. Naruko T, Ueda M, Haze K, van der Wal AC, van der Loos CM, Itoh A, Komatsu R, Ikura Y, Ogami M, Shimada Y, et al. Neutrophil infiltration of culprit lesions in acute coronary syndromes. Circulation. 2002;106(23):2894-900. 
51. Siminiak T, Flores NA, Sheridan DJ. Neutrophil interactions with endothelium and platelets: possible role in the development of cardiovascular injury. Eur Heart J. 1995;16(2):160-70.

52. Harlan JM, Killen PD, Harker LA, Striker GE, Wright DG. Neutrophil-mediated endothelial injury in vitro mechanisms of cell detachment. J Clin Invest. 1981;68(6):1394-403.

53. Chatzigeorgiou A, Karalis KP, Bornstein SR, Chavakis T. Lymphocytes in obesity-related adipose tissue inflammation. Diabetologia. 2012;55(10):2583-92.

54. Kanneganti TD, Dixit VD. Immunological complications of obesity. Nat Immunol. 2012;13(8):707-12.

55. Wu H, Ghosh S, Perrard XD, Feng L, Garcia GE, Perrard JL, Sweeney JF, Peterson LE, Chan L, Smith CW, et al. T-cell accumulation and regulated on activation, normal $T$ cell expressed and secreted upregulation in adipose tissue in obesity. Circulation. 2007;115(8):1029-38.
56. Afari ME, Bhat T. Neutrophil to lymphocyte ratio (NLR) and cardiovascular diseases: an update. Expert Rev Cardiovasc Ther. 2016;14(5):573-7.

57. Guo X, Zhang S, Zhang Q, Liu L, Wu H, Du H, Shi H, Wang C, Xia Y, Liu $X$, et al. Neutrophil:lymphocyte ratio is positively related to type 2 diabetes in a large-scale adult population: a Tianjin Chronic Low-Grade Systemic Inflammation and Health cohort study. Eur J Endocrinol. 2015;173(2):217-25.

58. Ryder E, Diez-Ewald M, Mosquera J, Fernandez E, Pedreanez A, Vargas $R$, Pena C, Fernandez N. Association of obesity with leukocyte count in obese individuals without metabolic syndrome. Diabetes Metab Syndr. 2014;8(4):197-204.

59. Lee CT, Harris SB, Retnakaran R, Gerstein HC, Perkins BA, Zinman B, Hanley AJ. White blood cell subtypes, insulin resistance and beta-cell dysfunction in high-risk individuals-the PROMISE cohort. Clin Endocrinol (Oxf). 2014;81(4):536-41.
Ready to submit your research? Choose BMC and benefit from:

- fast, convenient online submission

- thorough peer review by experienced researchers in your field

- rapid publication on acceptance

- support for research data, including large and complex data types

- gold Open Access which fosters wider collaboration and increased citations

- maximum visibility for your research: over $100 \mathrm{M}$ website views per year

At BMC, research is always in progress.

Learn more biomedcentral.com/submissions 